\title{
Simulated Effects of Dynamic Row Spacing on Energy and Water Conservation in Semi-Arid Central California Greenhouses
}

\author{
A. Moya, T. Mehlitz, I. Yildiz and S.F. Kelly \\ Department of BioResource \\ and Agricultural Engineering \\ California Polytechnic State University \\ San Luis Obispo, CA 93407 \\ USA
}

\author{
C. Hardin \\ Department of Mechanical Engineering \\ California Polytechnic State University \\ San Luis Obispo, CA 93407 \\ USA
}

Keywords: energy conservation, water conservation, transpiration, dynamic row spacing, passive heating, cooling

\begin{abstract}
Considerable effort is expended to conserve energy and water in current greenhouse systems, and look for alternative energy sources, especially passive heating and cooling strategies. Proper environmental management systems can significantly change the energy and moisture dynamics of greenhouse production systems. In this study, specifically, influences of dynamic row spacing on energy and water conservation were investigated. A dynamic computer simulation model was used to compare different row spacings, plant heights, and leaf dimensions to draw a conclusion about energy and water conservation. The results showed that using smaller spacings between cucumber crop rows (for instance, $0.5 \mathrm{~m}$ instead of $0.75 \mathrm{~m}$ ) reduced energy consumption per unit floor area in average of $14.4 \%$. With a decrease in row spacing, the total amount of surface for radiation exchange decreases, and plant canopy shading within the canopy increase consequently. This leads to less radiational and evaporative cooling in smaller row spacings, hence lower heating requirements during the heating season. By changing the row spacing from $0.75 \mathrm{~m}$ to $0.5 \mathrm{~m}$, average water savings (adjusted to the whole greenhouse area) of $27.8 \%$ occurred. A complete system analysis is necessary to be able to make a viable conclusion in total energy and water conservation.
\end{abstract}

\section{INTRODUCTION}

The California greenhouse industry is the largest in the U.S. with an area under glass, plastic or other protection over 5,000 acres accounting over $20 \%$ of all U.S. greenhouses (USDA, 2002). California's Gross Cash Income from the greenhouse, nursery and floriculture industry reached 3.3 billion dollars (California Department of Food and Agriculture, 2005). One major factor hindering future expansion of this industry, however, is the cost required for production inputs such as labor, water and energy. Large energy costs are frequently incurred to maintain the required thermal and radiant environments in greenhouses during both winter and summer seasons. Consequently, considerable effort is expended to conserve energy and look for alternative energy sources, especially passive heating and cooling strategies. Greenhouses in hot and arid regions also require large quantities of water for irrigation. Proper environmental management systems can significantly change the energy and moisture dynamics of greenhouse production systems. To provide economically optimal microenvironments for plant growth, designers and operators may employ a number of different management practices. The dynamic row spacing as well might play an important role for energy and water conservation, and have an influence on the plant growth. Papadopoulos and Pararajasingham (1997), in their extensive review, reported that greater yields of greenhouse crops could be produced by using narrow spacings (high plant density) compared with wide spacings. Increased fruit yield in narrow spacings result from greater crop biomass generated by the effect of increased light interception and canopy photosynthesis. A dynamic simulation model was developed and validated to provide an accurate prediction of greenhouse energy and moisture exchanges as a function of 
dynamic environmental factors (Yildiz and Stombaugh, 2006). This model was used to predict energy and water consumption using different (dynamic) row spacings, plant heights and leaf dimensions.

\section{MATERIALS AND METHODS}

\section{Weather File}

January, April, and July weather files for San Luis Obispo (35 $17^{\prime}$ N and $120^{\circ} 39^{\prime}$ W), California, USA were used to represent winter, spring, and summer in the simulations. Simulations were performed starting at the beginning of the fifth day and ended at the end of $29^{\text {th }}$ day of the month providing 25-day simulations. All simulations were performed for the years 2005, 2006 and 2007.

\section{Energy and Mass Balances}

The details of energy and moisture balances of the plant leaves, and the operational and control system characteristics were previously reported by Yildiz and Stombaugh (2006). However, it should be emphasized that stomatal resistance to water vapor in this study was defined only as a function of solar radiation, as explained by Yang et al. (1989). It is also worthwhile to provide a summary of energy and mass balances of other components in this article. In dealing with the energy and mass exchanges of the structural cover for instance, it was assumed that the exchanges occurred homogeneously on the cover, and that the heat storage capacity of the cover material was small compared to the existing fluxes, and no condensation or evaporation occurred on or from the cover. It was also assumed that, in this study, the floor was covered with a reflective polyethylene film. A one-dimensional heat conduction equation was used in dealing with the energy balance of the greenhouse floor, by dividing the floor into three layers $(0.01$, 0.10 and $0.50 \mathrm{~m}$ ) with the assumption of homogeneous thermal and hydraulic properties within each layer (Arinze, 1984; Avissar and Mahrer, 1982; Kindelan, 1980). It was also assumed that no condensation or evaporation occurred on or from the floor surface. The solar radiation was treated by splitting it into direct, diffuse and scattered components and assuming that all the radiation reflected by and/or transmitted through foliage elements contributed only to the diffuse component. The expression widely used in microclimatological studies for the penetration function of direct solar radiation for uniformly distributed plant canopies was expanded to a row plant stand whose foliage area distribution varied both vertically and horizontally. It was assumed that the scattering distributions (both upward and downward) were uniform horizontally. A resistance concept was used in dealing with the thermal radiation as outlined by Incropera and DeWitt (1985). A parallel plane analysis was employed whenever it was applicable. For the other cases, a complex multiple surface radiation exchange analysis using the resistance concept was employed.

\section{Greenhouse Characteristics and Analysis}

In this study, a conventional greenhouse system was used, having a natural gas fired furnace, an evaporative cooling system and a variable shading system. Table 1 shows the greenhouse and the crop characteristics used in this study. To draw a conclusion about energy consumption with respect to dynamic row spacing, two row spacings $(0.5 \mathrm{~m}$ and $0.75 \mathrm{~m})$ were used in this study (Table 1$)$. In addition to the row spacing, four plant heights and three leaf dimension sets were investigated (Table 1). All possible combinations of the above treatments for the three years and three seasons were studied, resulting in a total of 216 simulations. Daily mean values for the energy consumption for heating, and the water consumption for transpiration were determined for every season, year and treatment. The simulation findings were compared using standard Analysis of Variance (ANOVA) (significance level of $\mathrm{P}<0.05$ ). Tukey Simultaneous Test at a confidence level of $95 \%$ was performed to compare the means between the treatments, and statistically significant differences were observed. 


\section{RESULTS AND DISCUSSION}

\section{Energy Consumption for Heating}

The mean energy consumption for heating differed with the season and different row spacings. The colder the outside weather condition was, obviously the more heating energy was needed. The wider the row spacing was, the more energy was needed in all seasons (i.e., $0.5 \mathrm{~m}$ the least, $0.75 \mathrm{~m}$ the most) (Table 1, Figs. 1A, 2A and 3A). For the row spacing of $0.5 \mathrm{~m}$, the mean energy uses for heating were $28.3,21.5$, and 11.8 $\mathrm{MJ} / \mathrm{m}^{2} /$ day for winter, spring, and summer, respectively. For the row spacing of $0.75 \mathrm{~m}$, however, the mean energy uses for heating were $32.7,25.9$ and $13.5 \mathrm{MJ} / \mathrm{m}^{2} /$ day for winter, spring and summer, respectively. Statistical comparisons between all possible pairs were conducted using the Tukey Simultaneous Test at a 95\% confidence level. Table 2 shows that all of the presented means were statistically different from each other. The radiation exchange surfaces and airflow increased within wider row spacings; as a result, radiational, convective and evaporative cooling increased. Also, canopy shading decreased in wider row spacings; more plant surfaces were exposed to solar radiation inducing transpiration rates and evaporative cooling per unit floor area as a consequence. Therefore, the supplemental heating requirements in $0.75 \mathrm{~m}$ row spacing were higher. The row spacing could be kept just enough for the canopy stand, and increased dynamically as the crop grows and canopy stand gets larger. Our findings showed that such a practice could reduce supplemental heating requirement of a greenhouse, in average of $14.4 \%$ (Table 2).

Not only the row spacing, but also the plant height and the leaf dimensions were accountable for energy consumption. The most energy was needed when the plant stands were still short $(0.5-1.0 \mathrm{~m})$. As the plants grew, energy needs for heating went down depending on the season and final plant height (Figs. 1A, 2A and 3A). The energy consumption also depended on the leaf dimensions, and increased linearly with decreasing leaf area (Figs. 1A, 2A and 3A). These results are valuable to estimate different energy consumptions for specific plants, but are less important given that a greenhouse operator or designer usually has no choice which crop to grow with respect to energy consumption. However, this study showed that a greenhouse with tall plants had significantly less heating demand than a greenhouse with small plants (Figs. 1A, 2A, and $3 \mathrm{~A})$. This was because the taller plants overall had much less exposed surface area for radiation exchange. The space limitation here did not allow presenting the extensive findings of interactions between different variables.

One of the main factors on the energy consumption was the outside weather condition. The presented study was executed using weather data from three different years (2005, 2006 and 2007). Differences between the years were statistically significant as well, and varied depending on the season. For the winter and spring data sets, the energy consumption increased over the years, meaning that the year 2006 was colder than 2005; and the year 2007 was even colder than 2006. The summer data proved that the coldest summer was in the year 2005, followed by a warm summer in 2006, and then, relatively speaking, another cold summer in 2007 (Figs. 1A, 2A and 3A). Due to the space limitations, detailed climatic information could not be provided in the article. However, for the duration of the simulation period, the mean outside temperatures of three years were $9.6,11.5$ and $16.1^{\circ} \mathrm{C}$ in winter, spring and summer, respectively; the mean solar radiation received on a horizontal plane during daytime were 272, 396 and $466 \mathrm{~W} / \mathrm{m}^{2}$ in winter, spring and summer, respectively; and the mean outside relative humidity levels were $68.5,77.3$ and $80.4 \%$ in winter, spring and summer, respectively.

\section{Water Use for Transpiration}

Yildiz and Stombaugh (2006) reported that the model used in this study overestimated $(\sim 7 \%)$ the daytime inside relative humidities while underestimating $(\sim 10 \%)$ at night. This was due the fact that the stomatal resistance was derived from daytime data only, not counting for the effects of climatic variables other than solar 
radiation. Since the nighttime transpiration rates account for a very small portion of the total transpiration, the absolute magnitude of the error at night was not significant. As reported earlier in the abovementioned study, predicted and measured air and leaf temperatures were also in fairly good agreement. The predicted air temperatures by the model were slightly lower than the measured temperatures.

Simulation results of this dynamic model showed that, due to increased plant density within the whole greenhouse space, the water consumption increased in average of $8.5 \%$ as row spacing decreased (i.e., $0.50 \mathrm{~m}$ the most, $0.75 \mathrm{~m}$ the least water consumption). This is in agreement with the findings of Bryla and Strik (2007). However, in reality, for a dynamic row spacing system, plant density is kept the same throughout the growing season. Same number of plants exists no matter what the row spacing is. As crops grow, the row spacing expands covering larger greenhouse space during the growing season. Considering the $0.75 \mathrm{~m}$ spacing as the final row spacing covering the whole greenhouse floor area, the $0.5 \mathrm{~m}$ spacing transpiration figures can be adjusted for the whole greenhouse space (i.e., to the $0.75 \mathrm{~m}$ spacing) reducing the water consumption used in the whole greenhouse space (Table 2). Then, for the row spacing of $0.5 \mathrm{~m}$, the space adjusted mean water consumption for transpiration (of three years) was 1.72, 1.87 and $1.64 \mathrm{~kg} / \mathrm{m}^{2} /$ day for winter, spring and summer, respectively. For the row spacing of $0.75 \mathrm{~m}$, however, the mean water consumption for transpiration (of three years) was 2.46, 2.45 and $2.38 \mathrm{~kg} / \mathrm{m}^{2} /$ day for winter, spring and summer, respectively. Summer means show that less transpiration occurred in summer due to higher air moisture levels maintained inside the greenhouse (due to operational and control strategies employed) compared to those in winter and spring. Comparisons between all possible pairs were also made using the Tukey Simultaneous Test at a confidence level of 95\%. All of the presented means (of 0.5 and $0.75 \mathrm{~m}$ row spacings) for winter, spring, and summer were statistically different from each other. From $0.75 \mathrm{~m}$ to $0.50 \mathrm{~m}$ row spacing, the overall decrease in water consumption was in average of $27.8 \%$. The effect of row spacing definitely changes the dynamics of airflow in the canopy and it affects the canopy resistances, especially, the aerodynamic and stomatal resistances. It should however be emphasized that stomatal resistance to water vapor in this study was defined only as a function of solar radiation, as explained by Yang et al. (1989). The plant heights and leaf dimensions also played an important role with respect to the water consumption for transpiration. In general, the smaller the plants and the larger the leaves were, the less water was consumed (interactions not shown here). This observation is in agreement with previous studies by Claypool et al. (1997). In their study, they observed that large-leaved alfalfa plants had 10 to $16 \%$ lower transpiration than small (normal) leaves. The yield of large-leaved plants was also 17 to $22 \%$ higher than small-leaved. Our findings and this study indicate that crop transpiration can be improved by genetically changing leaf size to conserve water.

Different weather conditions had a major impact on the water consumption, showing that the colder the outside weather conditions were, the more water was consumed for transpiration due to increased vapor pressure deficit. Also, Figures $2 \mathrm{~B}$ and $3 \mathrm{~B}$ show that spring and summer seasons in 2006 had less transpiration compared to those in the other two years. This was because, compared to the years 2005 and 2007, the year 2006 had relatively lower incoming solar radiation in spring and summer seasons.

\section{CONCLUSION}

The findings in this study show that the energy consumption is dependent on the row spacing used in the greenhouse. The smaller the row spacing is, the less energy is consumed. If a smaller space requirement for a smaller row spacing is considered, then it will be clear that less greenhouse space is to be heated, increasing the potential to reduce energy consumption further. The growing space could be adjusted as the row spacing changes dynamically throughout the growing season, i.e., as the crop grows, the spacing must increase. A sophisticated design or modification of greenhouses using dynamic row spacing can therefore save both energy and water during the operational phase of the 
greenhouse. It seems that using smaller row spacing when the canopy stand is small could save both energy and water. Instead of using fixed row spacing throughout the growing season, one could employ dynamic row spacing using smaller row spacing when the canopy stand is small, and extending dynamically as the canopy stand gets larger. Also, the smaller the plants and the larger the leaves were, the less water was consumed. Our findings indicate that crop transpiration can be improved by genetically modifying crop leaf sizes and canopy stands. However, to be able to make a conclusion about total energy and water conservation, the greenhouse has to be seen as a complete system. Potential energy savings due to dynamic row spacing have to be seen in conjunction with the energy expenditure or labor required for providing such a system. Therefore, a total energy and water conservation analysis has to be conducted for each case separately, considering the infrastructure, local water, energy and labor costs and also the crop type.

\section{ACKNOWLEDGEMENTS}

The authors would like to extend their appreciation to BioResource and Agricultural Engineering Department for providing partial funding.

\section{Literature Cited}

Arinze, E.A., Schoenau, G.J. and Besant, R.W. 1984. A dynamic thermal performance simulation model of an energy conserving greenhouse with thermal storage. Transactions of the ASAE 27:508-519.

Avissar, R. and Mahrer, Y. 1982. Verification study of a numerical greenhouse microclimate model. Transactions of the ASAE 25:1711-1720.

Bryla, D.R. and Strik, B.C. 2007. Effects of cultivar and plant spacing on the seasonal water requirements of highbush blueberry. J. Amer. Soc. Hort. Sci. 132(2):270-277.

California Department of Food and Agriculture. "California Agricultural Overview California Agricultural Resource Directory, 2005."

Claypool, D., Delaney, R., Ditterline, R. and Lockerman, R. 1997. Genetic improvement of alfalfa to conserve water. Poster Presentation, Wyoming Water 1997 Conference, April 21-23, Casper, W.Y.

Incropera, F.P. and DeWitt, D.P. 1985. Introduction to Heat Transfer. John Wiley \& Sons, Inc. New York, USA.

Kindelan, M. 1980. A dynamic modeling of greenhouse environment. Transactions of the ASAE 23(5):1232-1239.

Papadopoulos, A.P. and Pararajasingham, S. 1997. The influence of plant spacing on light interception and use in greenhouse tomato (Lycopersicon esculentum Mill.): A review. Scientia Horticulturae (69): 1-29.

USDA. "2002 Census of Agriculture - State Data (California)", National Agricultural Statistics Service.

Yang, X., Short, T.H., Fox, R.D. and Bauerle, W.L. 1989. The microclimate and transpiration of a greenhouse cucumber crop. Trans. of the ASAE 32(6):2143-2150.

Yildiz, I. and Stombaugh, D.P. 2006. Dynamic modeling of microclimate and environmental control strategies in a greenhouse coupled with a heat pump system. Acta Hort. 718:331-340. 


\section{$\underline{\text { Tables }}$}

Table 1. Greenhouse and crop characteristics used in the simulation model.

\begin{tabular}{ll} 
Greenhouse length & $15.0 \mathrm{~m}$ \\
Greenhouse width & $7.50 \mathrm{~m}$ \\
Greenhouse height at eaves & $2.50 \mathrm{~m}$ \\
Greenhouse height at ridges & $4.50 \mathrm{~m}$ \\
Glazing & Double polyethylene \\
Floor surface material & Reflective mulch; $60 \%$ reflectivity \\
Crop type & Cucumber \\
Crop row orientation & North - South \\
Distance between plant rows & $0.5 \mathrm{~m}$ and $0.75 \mathrm{~m}$ \\
Avg. leaf length x width & Set $1: 0.30 \times 0.25 \mathrm{~m}$, Set $2: 0.23 \times 0.18 \mathrm{~m}$, \\
Avg. plant height & Set $3: 0.15 \times 0.10 \mathrm{~m}$ \\
& $0.5 \mathrm{~m}, 0.75 \mathrm{~m}, 1.0 \mathrm{~m}, 1.5 \mathrm{~m}, 2.0 \mathrm{~m}$ \\
\hline
\end{tabular}

Table 2. Comparisons of energy and water consumption means with respect to different row spacings using the Tukey Simultaneous Test at a 95\% confidence level.

\begin{tabular}{|c|c|c|c|c|c|c|c|c|}
\hline & \multicolumn{4}{|c|}{ Energy use (all values in $\mathrm{MJ} / \mathrm{m}^{2} /$ day) } & \multicolumn{4}{|c|}{ Water use (all values in $\mathrm{kg} / \mathrm{m}^{2} /$ day) } \\
\hline & $\begin{array}{l}\text { Row } \\
\text { Spacing } \\
\text { (Mean) }\end{array}$ & $\begin{array}{l}\text { Compared to } \\
\text { row spacing } \\
\text { (Mean) }\end{array}$ & $\begin{array}{l}\text { Difference } \\
\text { of Means }\end{array}$ & $\begin{array}{c}\text { Statistically } \\
\text { Significant at } \\
\text { a } 95 \% \text { level? }\end{array}$ & $\begin{array}{l}\text { Row } \\
\text { Spacing } \\
\text { (Mean) }\end{array}$ & $\begin{array}{l}\text { Compared to } \\
\text { row spacing } \\
\text { (Mean) }\end{array}$ & $\begin{array}{l}\text { Difference } \\
\text { of Means }\end{array}$ & $\begin{array}{c}\text { Statistically } \\
\text { Significant at } \\
\text { a } 95 \% \text { level? }\end{array}$ \\
\hline 兽 & $0.5(28.3)$ & $0.75(32.7)$ & 4.4 & YES & $0.5(1.72)$ & $0.75(2.46)$ & 0.74 & YES \\
\hline 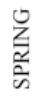 & $0.5(21.5)$ & $0.75(25.9)$ & 4.4 & YES & $0.5(1.87)$ & $0.75(2.45)$ & 0.58 & YES \\
\hline 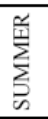 & $0.5(11.8)$ & $0.75(13.5)$ & 1.7 & YES & $0.5(1.64)$ & $0.75(2.38)$ & 0.74 & YES \\
\hline
\end{tabular}




\section{$\underline{\text { Figures }}$}
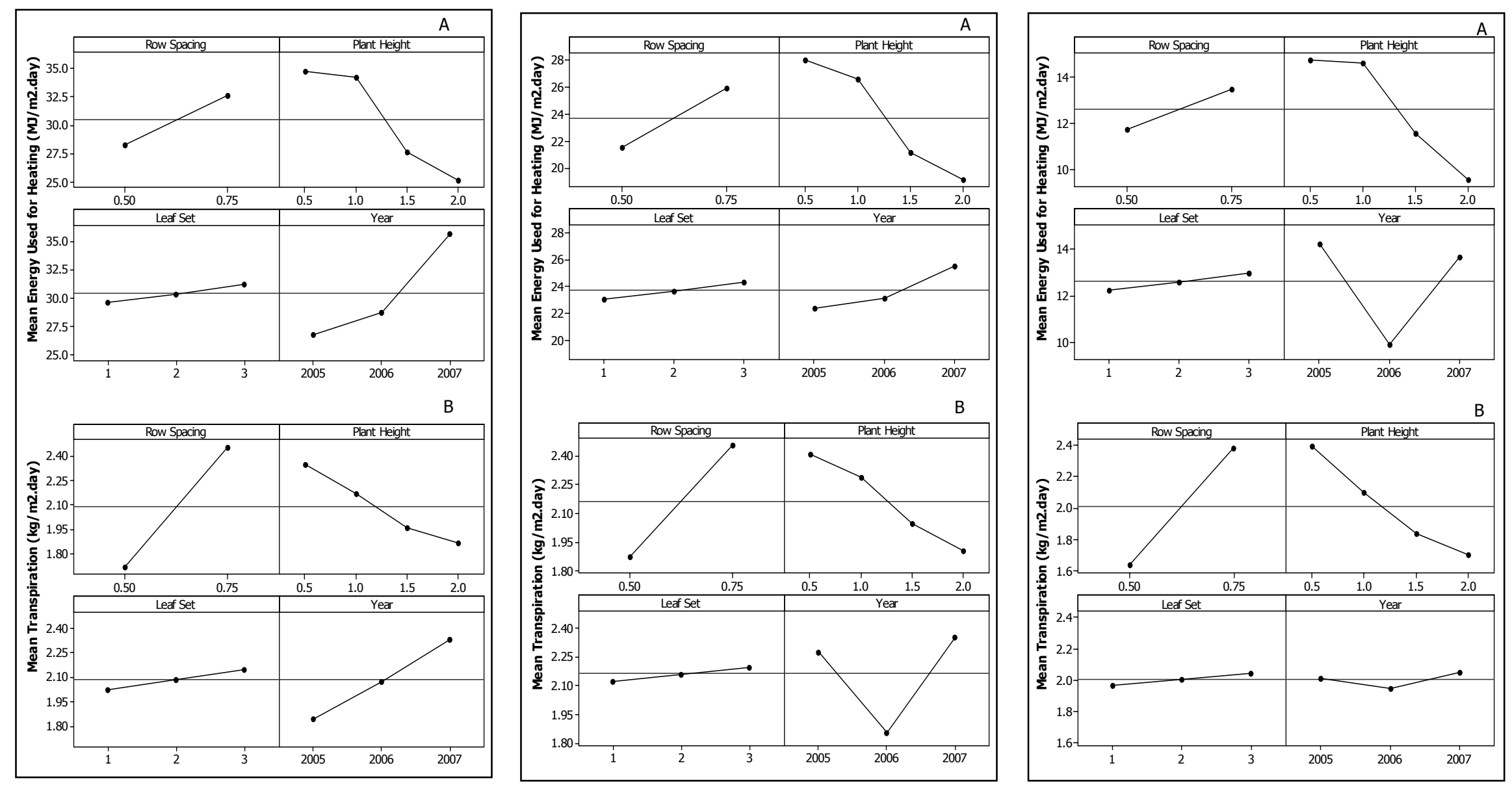

Fig. 1. Main Effects Plot - Energy use for Fig. 2. Main Effects Plot - Energy use for Fig. 3. Main Effects Plot - Energy use for heating (A) and transpiration (B) in winter. Presented are the fitted heating (A) and transpiration (B) in spring. Presented are the fitted means. heating (A) and transpiration (B) in summer. Presented are the fitted means. means. 